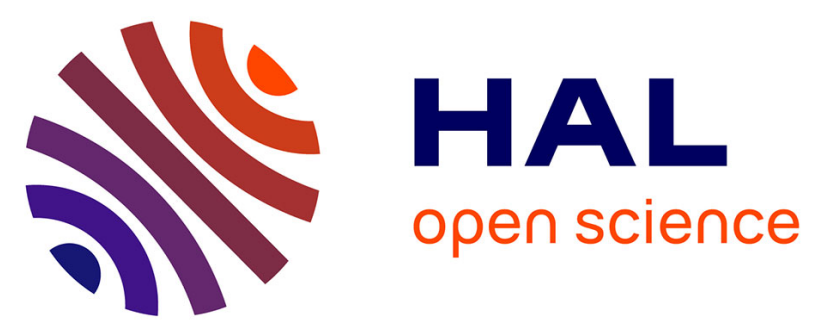

\title{
Antioxidant properties of 3-deoxyanthocyanidins and polyphenolic extracts from Côte d'Ivoire's red and white sorghums assessed by ORAC and in vitro LDL oxidisability tests
}

Marie-Annette Carbonneau, Moctar Cisse, Nathalie Mora-Soumille, Sofiane

Dairi, Maxence Rosa, Françoise Michel, Céline Lauret, Jean-Paul Cristol, Olivier O. Dangles

\section{- To cite this version:}

Marie-Annette Carbonneau, Moctar Cisse, Nathalie Mora-Soumille, Sofiane Dairi, Maxence Rosa, et al.. Antioxidant properties of 3-deoxyanthocyanidins and polyphenolic extracts from Côte d'Ivoire's red and white sorghums assessed by ORAC and in vitro LDL oxidisability tests. Food Chemistry, 2014, 145, pp.701-709. 10.1016/j.foodchem.2013.07.025 . hal-02634650

\section{HAL Id: hal-02634650 \\ https://hal.inrae.fr/hal-02634650}

Submitted on 27 May 2020

HAL is a multi-disciplinary open access archive for the deposit and dissemination of scientific research documents, whether they are published or not. The documents may come from teaching and research institutions in France or abroad, or from public or private research centers.
L'archive ouverte pluridisciplinaire HAL, est destinée au dépôt et à la diffusion de documents scientifiques de niveau recherche, publiés ou non, émanant des établissements d'enseignement et de recherche français ou étrangers, des laboratoires publics ou privés. 


\title{
Antioxidant properties of 3-deoxyanthocyanidins and polyphenolic extracts from Côte d'Ivoire's red and white sorghums assessed by ORAC and in vitro LDL oxidisability tests
}

\author{
Marie-Annette Carbonneau ${ }^{\mathrm{a}, *}$, Moctar Cisse $^{\mathrm{a}, \mathrm{b}}$, Nathalie Mora-Soumille ${ }^{c}$, Sofiane Dairi ${ }^{a}$, Maxence Rosa ${ }^{c}$, \\ Françoise Michel $^{\mathrm{a}, \mathrm{d}}$, Céline Lauret ${ }^{\mathrm{a}}$, Jean-Paul Cristol ${ }^{\mathrm{a}, \mathrm{d}}$, Olivier Dangles ${ }^{\mathrm{c}}$ \\ ${ }^{a}$ UMR 204 NUTRIPASS, University Institute of Clinical Research, 641, Av. Doyen Gaston Giraud, 34093 Montpellier Cedex 5, France \\ ' INPHB, 1093 Yamoussoukro, Côte d'Ivoire \\ ${ }^{\mathrm{C}}$ University of Avignon, INRA, UMR 408, 84000 Avignon, France \\ ${ }^{\mathrm{d}}$ Department of Biochemistry, Lapeyronie Hospital, CHRU 371, Av. Doyen Gaston Giraud, 34295 Montpellier Cedex 5, France
}

\begin{abstract}
A B S T R A C T
Red sorghum is a source of phenolic compounds (PCs), including 3-deoxyanthocyanidins that may protect against oxidative stress related disease such as atherosclerosis. HPLC was used to characterise and quantify PCs extracted from red or white sorghum whole grain flour. Antioxidant activity was measured by an oxygen radical absorbance capacity assay and against LDL-oxidisability, and further compared to that of synthesised 3-deoxyanthocyanidins (i.e., luteolinidin and apigeninidin). Phenolic content of red and white sorghums was evaluated as $3.90 \pm 0.01$ and $0.07 \pm 0.01 \mathrm{mmol}$ gallic acid equivalents $\mathrm{L}^{-1}$, respectively. Luteolinidin and apigeninidin were mainly found in red sorghum. Red sorghum had almost 3 and 10 times greater specific antioxidant activity compared to luteolinidin and apigeninidin, respectively. Red sorghum PCs and the two 3-deoxyanthocyanidins were also effective at preventing LDL vitamin E depletion and conjugated diene production. Red sorghum flour exhibits antioxidant capacity suggesting that it may be a valuable health-promoting food.
\end{abstract}

3-Deoxyanthocyanidins, apigeninidin, luteolinidin

Sorghum polyphenols

Oxygen radical absorption capacity

Low density lipoprotein oxidation

Vitamin E

\section{Introduction}

Sorghum bicolor (L.) Moench is one of the most important cereal crops in the world. Sorghum is the staple food in several countries, notably in Africa. In West Africa, non-germinated sorghum grain is generally used for the preparation of "tô" (thick porridge) and couscous (granulated food). Malted sorghum is often used for infant food (thin porridge), for production of a local beer ("dolo") and non-fermented beverages.

Sorghum contains significant quantities of phenolic acids like hydroxybenzoic and hydroxycinnamic acids. Moreover, anthocyanins are the major flavonoid class in sorghum. In general, these pigments contribute to the blue, purple, and red colours in plants (Awika, Rooney, \& Waniska, 2004; Yoshida, Mori, \& Kondo, 2009), and possess antioxidant and anti-inflammatory properties that may be relevant in the prevention of chronic diseases (Tsuda, 2012). Sorghum anthocyanidins (anthocyanin aglycones) are unique since they do not display a hydroxyl group in the C-ring 3-position (Fig. 1) and thus are called 3-deoxyanthocyanidins (3-DAs). This unique feature increases their chemical stability at

\footnotetext{
* Corresponding author. Tel.: +33 411759892; fax: +33 467542731.

E-mail address: marie-annette.carbonneau@univ-montp1.fr (M.-A. Carbonneau).
}

neutral pH compared to the common anthocyanidins. The two common sorghum 3-DAs, namely apigeninidin [1] and luteolinidin [2], are especially abundant in sorghum grains but rare or absent in other plants (Awika et al., 2004). These polyphenols could present a potential for additional health benefits to consumers, for instance by reducing the incidence of oesophageal and gastrointestinal cancers as shown by epidemiological studies (Isaacson, 2005) or in vitro inhibition of cell proliferation (Awika, Yang, Browning, \& Faraj, 2009). On the other hand, the inhibition of LDL oxidation has been widely used to analyse the antioxidant activity of natural products (mainly composed of phenolic acids, flavanols or flavonols) in relation to protection against cardiovascular disease (Cartron, Carbonneau, Fouret, Descomps, \& Léger, 2001; Monde et al., 2011). However, no data are available concerning the effects of sorghum polyphenols and particularly the effects of 3-DAs on the inhibition of LDL oxidation.

The aim of this work was to synthesise red sorghum anthocyanidins (3-DAs) and compare their oxygen radical absorption capacity (ORAC) and their ability to protect low-density lipoprotein (LDL) against in vitro oxidation - initiated by $\mathrm{Cu}^{2+}$ ions or the diazo compound 2,2'-azobis (2-amidinopropane dihydrochloride (AAPH) - with that of red and white sorghum polyphenolic compounds (PCs). LDL oxidation was monitored by conjugated diene formation 

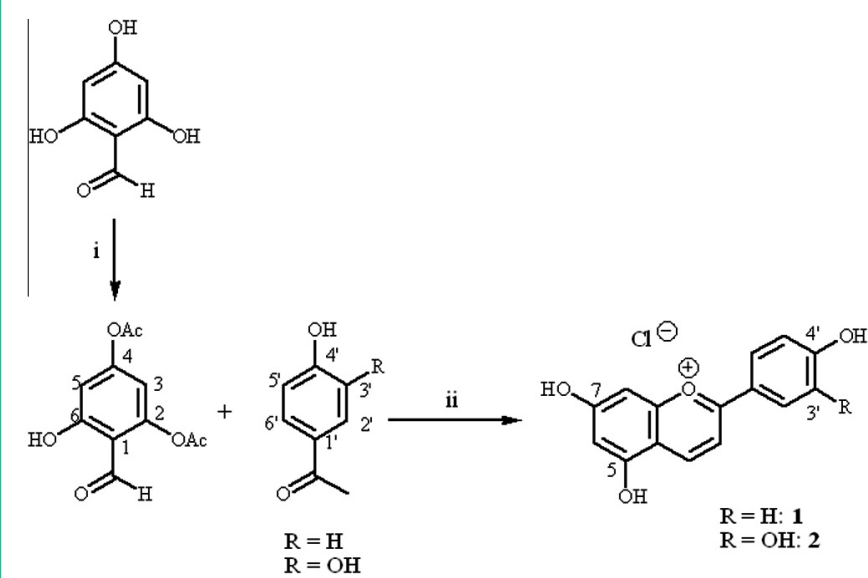

Fig. 1. Chemical synthesis of 3-deoxyanthocyanidins, apigeninidin [1] and luteolinidin [2]. (i) Partial acetylation for improved solubility in EtOAc and inhibition of acid-catalysed polymerisation: $\mathrm{Ac}_{2} \mathrm{O}$ (2 equiv.), DMAP ( 0.2 equiv.), EtOAc. (ii) Construction of the flavylium nucleus (one-pot acid-catalysed aldol condensation followed by intramolecular hemiketal formation and dehydration): gaseous $\mathrm{HCl}$, EtOAc. (iii) Deacetylation: MeONa (10 equiv.), $\mathrm{MeOH}$, then acidification by aq. $\mathrm{HCl}$.

and protection of LDL-vitamin E. If beneficial effects of biologically active sorghum PCs on LDL-vitamin E protection exist, these data could also be used in food-based dietary guidelines for healthier nutrition or for the management of chronic diseases by a polyphenol-rich diet. Moreover, the lack of oxygen at C-3 in 3-DAs could improve their stability and give a potential advantage of sorghum PCs as a viable commercial source of antioxidants (Awika et al., 2004).

\section{Materials and methods}

\subsection{Materials and chemicals}

All starting materials were obtained from commercial suppliers and were used without purification. Ethyl acetate (AcOEt) was distilled over 4 Å molecular sieves. Thin-layer chromatography (TLC) analyses were performed on silica gel Merck $\mathrm{F}_{254}$ or $\mathrm{C}-18$ silica gel F254s. Detection was achieved by UV spectroscopy $(254 \mathrm{~nm})$ and by charring after exposure to a $5 \% \mathrm{H}_{2} \mathrm{SO}_{4}$ solution in ethanol (EtOH). Purifications were performed by column chromatography on silica gel Merck Si60 $(40-63 \mu \mathrm{m})$ and Varian Bond Elut Cartridges $\mathrm{C} 18 .{ }^{1} \mathrm{H}$ and ${ }^{13} \mathrm{C}$ NMR spectra were recorded on a Bruker Avance DPX-300 apparatus at $300.13 \mathrm{MHz}\left({ }^{1} \mathrm{H}\right)$ or $75.46 \mathrm{MHz}$ $\left({ }^{13} \mathrm{C}\right)$. NMR chemical shifts are in parts per million relative to tetramethylsilane using the deuterium signal of the solvent for calibration, ${ }^{1} \mathrm{H}-{ }^{1} \mathrm{H}$ coupling constants $(J)$ are in hertz $(\mathrm{Hz})$. Highresolution mass analyses (HR-MS) were carried out on a Qstar Elite instrument (Applied Biosystems SCIEX, Foster City, CA) equipped with API. Mass detection was performed in the negative or positive electrospray ionisation mode. HPLC-DAD analyses were performed using a Waters HPLC system consisting of a Waters 600E pump, a Waters 717 autosampler, a Waters 2996 photodiode array detector, a Waters In-line Degasser AF degasser and a Millennium workstation. A LichroCART 250-4 Lichrospher 100 RP-18e column $(250 \times 4.6 \mathrm{~mm}, 5 \mu \mathrm{m}$ particle size) was used for chromatographic separations at $25^{\circ} \mathrm{C}$. The solvent system was a gradient of $\mathrm{A}(5 \%$ $\mathrm{HCO}_{2} \mathrm{H}$ in $\left.\mathrm{MeCN} / \mathrm{H}_{2} \mathrm{O} 1 / 1\right)$ and $\mathrm{B}\left(5 \% \mathrm{HCO}_{2} \mathrm{H}\right.$ in $\left.\mathrm{H}_{2} \mathrm{O}\right)$ with $10 \% \mathrm{~A}$ at $0 \mathrm{~min}$ and $100 \% \mathrm{~A}$ at $60 \mathrm{~min}$ (flow rate $=1 \mathrm{~mL} / \mathrm{min}$ ). UV-Vis spectroscopy was performed on an Agilent 8453 diode array spectrometer equipped with a magnetically stirred quartz cell (optical path length $=1 \mathrm{~cm}$ ). The temperature in the cell was controlled by means of a water thermostated bath at $25 \pm 0.1{ }^{\circ} \mathrm{C}$.
Sorghum bicolor (L.) Moench grains were purchased from Côte d'Ivoire at several markets in Abidjan and the interior of the country, then mixed and cleaned to remove debris. $\mathrm{CuCl}_{2}$, butylated hydroxytoluene (BHT) and the $2 \mathrm{~N}$ Folin-Ciocalteu reagent were obtained from Sigma Aldrich (Saint Quentin Fallavier, France), while gallic acid and ultra-gradient grade methanol for high-performance liquid chromatography (HPLC) were purchased from Merck (Darmstadt, Germany). AAPH was from Biovalley (Conches, France). Other chemicals used are either reagent grade or HPLC grade. Trolox (6-hydroxy-2,3,7,8-tetramethylchroman-2-carboxylic acid) and 2'7'-dichlorofluorescein were from Aldrich and Merck, respectively.

\subsection{Chemical synthesis 3',4'-dihydroxyacetophenone}

A mixture of activated zinc powder ( $5 \mathrm{~g}, 76 \mathrm{mmol}), \omega$-chloro3,4-dihydroxyacetophenone ( $5 \mathrm{~g}, 27 \mathrm{mmol})$, THF $(120 \mathrm{~mL})$ and acetic acid $(30 \mathrm{~mL})$ was vigorously stirred for 3 days at room temperature. After filtration and concentration under reduced pressure, $100 \mathrm{~mL}$ of EtOAc were added. The organic layer was washed with water $(3 \times 100 \mathrm{~mL})$, dried over $\mathrm{Na}_{2} \mathrm{SO}_{4}$ and evaporated. The crude product was purified by column chromatography $\left(\mathrm{SiO}_{2}, \mathrm{cHex} /\right.$ EtOAc, $\left.1: 1 \mathrm{v} / \mathrm{v}\right)$ to give compound 3,4-dihydroxyacetophenone as a white amorphous powder: yield, 90\%; $R_{f}$ (cHex/ EtOAc, $1: 1), 0.47 ;{ }^{1} \mathrm{H}-\mathrm{NMR}\left(\mathrm{CDCl}_{3}\right), \delta 7.67\left(1 \mathrm{H}, \mathrm{d}, J=2.0, \mathrm{H}_{2^{\prime}}\right), 7.55$ $\left(1 \mathrm{H}, \mathrm{dd}, J=2.0\right.$ and $\left.8.3 \mathrm{~Hz}, \mathrm{H}_{6^{\prime}}\right) ; 6.96\left(1 \mathrm{H}, \mathrm{d}, J=8.3 \mathrm{~Hz}, \mathrm{H}_{5^{\prime}}\right), 6.19$ $(1 \mathrm{H}, \mathrm{s}, \mathrm{OH}), 5.99(1 \mathrm{H}, \mathrm{s}, 1 \mathrm{OH}), 2.53\left(\mathrm{~s}, 3 \mathrm{H}, \mathrm{COCH}_{3}\right)$; HPLC-DAD $-t_{\mathrm{R}} 14.2 \mathrm{~min}, \lambda_{\max }: 276 \mathrm{~nm}$.

2,4-Diacetoxy-6-hydroxybenzaldehyde and 4-acetoxy-2,6-dihydroxybenzaldehyde. 2,4,6-Trihydroxybenzaldehyde (1.85 g, $12 \mathrm{mmol}$ ) and $\mathrm{N}, \mathrm{N}$-dimethylaminopyridine ( 0.2 equiv) were dissolved in EtOAc $(50 \mathrm{~mL})$. Acetic anhydride (2 equiv) was added and the mixture was refluxed for $5 \mathrm{~h}$. After washings with $1 \mathrm{M}$ $\mathrm{HCl}(2 \times 100 \mathrm{~mL})$ and water $(2 \times 100 \mathrm{~mL})$, the organic layer was dried over $\mathrm{Na}_{2} \mathrm{SO}_{4}$ and concentrated under reduced pressure. The residue was purified by chromatography on silica gel $\left(\mathrm{SiO}_{2}, \mathrm{cHex}\right)$ EtOAc, 95:5 v/v) to afford a mixture of mono- and diacetylated compounds. Only, 2,4-diacetoxy-6-hydroxybenzaldehyde could be separated as a white amorphous powder and identified: yield, 65\%; $R_{f}$ (cHex/EtOAc, 7:3), 0.47; ${ }^{1} \mathrm{H} \mathrm{NMR}\left(\mathrm{CDCl}_{3}\right), \delta 6.67(1 \mathrm{H}, \mathrm{d}$, $\left.J=1.9, \mathrm{H}_{5}\right), 6.63\left(1 \mathrm{H}, \mathrm{d}, J=1.9, \mathrm{H}_{3}\right), 2.39(3 \mathrm{H}, \mathrm{s}, \mathrm{Ac}), 2.32(3 \mathrm{H}, \mathrm{s}, \mathrm{Ac})$. 4,5,7-Trihydroxyflavylium chloride = apigeninidin [1]. Equimolar amounts $(2 \mathrm{mmol})$ of 4-hydroxyacetophenone and a mixture of 2,4-diacetoxy-6-hydroxybenzaldehyde and 4-acetoxy-2,6-dihydroxybenzaldehyde were dissolved in distilled EtOAc $(30 \mathrm{~mL})$ and cooled to $0{ }^{\circ} \mathrm{C}$. Gaseous $\mathrm{HCl}$ (generated by action of $98 \% \mathrm{H}_{2} \mathrm{SO}_{4}$ on solid $\mathrm{NaCl}$ ) was gently bubbled through the solution for $90 \mathrm{~min}$. The mixture was kept at $4{ }^{\circ} \mathrm{C}$ for 3 days, and then filtered. More precipitate was collected after evaporation of the filtrate and addition of diethyl ether $\left(\mathrm{Et}_{2} \mathrm{O}\right)$. After precipitation in EtOAc, the red powder obtained was dissolved in dry methanol $(\mathrm{MeOH})(20 \mathrm{~mL})$ and treated with $\mathrm{MeONa}$ (10 equiv) under $\mathrm{N}_{2}$. After $90 \mathrm{~min}$ at room temperature, the solution was carefully acidified to $\mathrm{pH} 1-3$ (wet $\mathrm{pH}$ paper) with $1 \mathrm{M} \mathrm{HCl}$, then kept overnight at $4{ }^{\circ} \mathrm{C}$. After evaporation, the crude powder containing [1], $\mathrm{NaCl}$ and residual starting materials resulting from incomplete condensation, was dissolved in $0.01 \mathrm{M} \mathrm{HCl}(2 \mathrm{~mL})$. The solution was eluted on reversed-phase silica gel (Bond Elut cartridges C18, particle size 40-63 $\mu \mathrm{m}$; Agilent) to afford pure [1]. Overall yield for condensation, deacetylation and purification: 62\%; $R_{f}\left(\mathrm{nBuOH} / \mathrm{HOAc} / \mathrm{H}_{2} \mathrm{O}, 3: 2: 1\right), 0.83$. The purity of [1] was carefully checked by reverse-phase HPLCDAD with detection at $280 \mathrm{~nm}$. The sole peak detected displayed a UV/Vis spectrum typical of anthocyanins: $t_{\mathrm{R}} 29.2 \mathrm{~min}, \lambda_{\max }$ $471 \mathrm{~nm}$. UV/Vis ( $\mathrm{pH} 3$ citrate buffer), $\varepsilon=22400 \mathrm{M}^{-1} \mathrm{~cm}^{-1}$ at $468 \mathrm{~nm} .{ }^{1} \mathrm{H}-\mathrm{NMR}$ (DMSO-d $\left.\mathrm{d}_{6} / 0.2 \mathrm{M} \mathrm{TFA}\right), \delta 9.04\left(1 \mathrm{H}, \mathrm{d}, J=8.7, \mathrm{H}_{4}\right)$, $8.35\left(1 \mathrm{H}, \mathrm{d}, J=8.7, \mathrm{H}_{3}\right), 8.15\left(2 \mathrm{H}, \mathrm{d}, J=8.8, \mathrm{H}_{2^{\prime}}, \mathrm{H}_{6^{\prime}}\right), 7.07(2 \mathrm{H}, \mathrm{d}$, 
$\left.J=8.8, \mathrm{H}_{3^{\prime}}, \mathrm{H}_{5^{\prime}}\right), 6.97\left(1 \mathrm{H}, \mathrm{s}, \mathrm{H}_{8}\right), 6.72\left(1 \mathrm{H}, \mathrm{s}, \mathrm{H}_{6}\right) ;{ }^{13} \mathrm{C}-\mathrm{NMR}$ (DMSO$\mathrm{d}_{6} / 0.2$ M TFA $), \delta 172.3\left(\mathrm{C}_{7}\right), 172.2\left(\mathrm{C}_{2}\right), 168.2\left(\mathrm{C}_{4^{\prime}}\right), 160.1\left(\mathrm{C}_{5}\right), 160.0$ $\left(C_{9}\right), 149.7\left(C_{4}\right), 133.9\left(C_{2^{\prime}}, C_{6^{\prime}}\right), 121.9\left(C_{1^{\prime}}\right), 118.1\left(C_{3^{\prime}}, C_{5^{\prime}}\right), 113.6$ $\left(\mathrm{C}_{10}\right), 110.5\left(\mathrm{C}_{3}\right), 103.1\left(\mathrm{C}_{6}\right), 96.3\left(\mathrm{C}_{8}\right)$; HRMS-ESI, $\mathrm{m} / z\left(\mathrm{M}^{+}\right)$calculated for $\mathrm{C}_{15} \mathrm{H}_{11} \mathrm{O}_{4}^{+}, 255.0652$; found, 255.0651 .

3',4',5,7-Tetrahydroxyflavylium chloride = luteolinidin [2]. Same procedure as for [1] replacing 4-hydroxyacetophenone by 3,4dihydroxyacetophenone. After deacetylation, reacidification and purification on reversed-phase silica gel, [2] was obtained as a HPLC-pure red powder: overall yield, $71 \% ; R f\left(\mathrm{nBuOH} / \mathrm{HOAc} / \mathrm{H}_{2} \mathrm{O}\right.$, $3: 2: 1), 0.77$; The purity of [2] was carefully checked by reversephase HPLC-DAD with detection at $280 \mathrm{~nm}$. The sole peak detected displayed a UV/Vis spectrum typical of anthocyanins: $t_{\mathrm{R}} 26.9 \mathrm{~min}$, $\lambda_{\max } 485 \mathrm{~nm}$. UV/Vis (pH 3 citrate buffer), $\varepsilon=19600 \mathrm{M}^{-1} \mathrm{~cm}^{-1}$ at $481 \mathrm{~nm} .{ }^{1} \mathrm{H}-\mathrm{NMR}$ (DMSO-d $6 / 0.2 \mathrm{M} \mathrm{TFA}$ ), $\delta 8.99\left(1 \mathrm{H}, \mathrm{d}, J=8.7, \mathrm{H}_{4}\right)$; $8.08\left(1 \mathrm{H}, \mathrm{d}, J=8.7, \mathrm{H}_{3}\right), 7.91\left(1 \mathrm{H}, \mathrm{d}, J=8.8, \mathrm{H}_{6^{\prime}}\right), 7.78\left(1 \mathrm{H}, \mathrm{s}, \mathrm{H}_{2^{\prime}}\right)$, $7.06\left(1 \mathrm{H}, \mathrm{d}, J=8.8, \mathrm{H}_{5^{\prime}}\right), 6.96\left(1 \mathrm{H}, \mathrm{s}, \mathrm{H}_{8}\right), 6.78\left(1 \mathrm{H}, \mathrm{s}, \mathrm{H}_{6}\right) ;{ }^{13} \mathrm{C}-$ NMR (DMSO-d $\mathrm{d}_{6} / 0.2 \mathrm{M}$ TFA), $\delta 172.3\left(\mathrm{C}_{7}\right), 172.2\left(\mathrm{C}_{2}\right), 160.1\left(\mathrm{C}_{5}\right)$, $160.0\left(C_{9}\right), 157.2\left(C_{4^{\prime}}\right), 149.7\left(C_{4}\right), 148.0\left(C_{3^{\prime}}\right), 126.4\left(C_{6^{\prime}}\right), 122.2$ $\left(C_{1^{\prime}}\right), 118.0\left(C_{5^{\prime}}\right), 116.1\left(C_{2^{\prime}}\right), 113.4\left(C_{10}\right), 110.5\left(C_{3}\right), 103.0\left(C_{6}\right)$, 96.1 $\left(\mathrm{C}_{8}\right)$; HRMS-ESI, $\mathrm{m} / \mathrm{z}\left(\mathrm{M}^{+}\right)$calculated for $\mathrm{C}_{15} \mathrm{H}_{11} \mathrm{O}_{5}{ }^{+}$, 271.0601 ; found, 271.0606 .

\subsection{Whole flour sample preparation, polyphenol extraction and quantification}

\subsubsection{Preparation of whole flour and sample extraction}

Samples of sorghum grain (collected on different markets and mixed) were powdered in a 'Disk Mill' (Glen Mills Inc., Clifton, $\mathrm{NJ}$ ) and the whole flour was employed in this study. The extraction procedure involved the addition of $50 \mathrm{~mL}$ EtOH and $50 \mathrm{~mL} \mathrm{H}_{2} \mathrm{O}$ acidified by acetic acid ( $\mathrm{pH} 2.6$ ) to $10 \mathrm{~g}$ of whole flour to obtain an acidic ethanol/water extract $\left(\mathrm{EWH}^{+}\right)$. The sample was shaken for $3 \mathrm{~h}$ at room temperature and centrifuged at $3000 \mathrm{~g}$ for $10 \mathrm{~min}$. The supernatant was then concentrated on a Rotavapor at $40{ }^{\circ} \mathrm{C}$ to a final volume of $25 \mathrm{~mL}$. The extraction procedure was carried out at least in triplicate. The $\mathrm{EWH}^{+}$method, like the acidified $(1 \% \mathrm{HCl})$ methanol extraction (Awika et al., 2004), was very efficient for the extraction of total anthocyanins. The $\mathrm{EWH}^{+}$method was used for HPLC and spectral analyses. Then, $2 \mathrm{~mL} \mathrm{EWH}^{+}$were added to $8 \mathrm{~mL} \mathrm{CHCl}_{3}$ and $10 \mathrm{~mL} \mathrm{H}_{2} \mathrm{O}$. The sample was then vortexed and centrifuged at $3000 \mathrm{~g}$ for $10 \mathrm{~min}$ (Eppendorf centrifuge 5804R, Dutscher SA, Brumath, France) to obtain $11 \mathrm{~mL}$ of an aqueous extract of polyphenolic compounds $\left(\mathrm{EWH}^{+}-\mathrm{PC}\right)$. This procedure was carried out for removing the more hydrophobic compounds $\left(\mathrm{CHCl}_{3}\right.$ phase) and was systematically applied prior to the ORAC and LDL oxidation tests.

\subsubsection{Determination of phenol content}

The phenolic amount in $\mathrm{EWH}^{+}$-PC was determined with the Folin-Ciocalteu reagent according to a modified procedure (Waterhouse, 2001), using gallic acid as a standard: $200 \mu \mathrm{L}$ of diluted PCs and $100 \mu \mathrm{L}$ of Folin-Ciocalteu reagent diluted in $1.4 \mathrm{~mL} \mathrm{H}_{2} \mathrm{O}$ were placed into tubes and $300 \mu \mathrm{L}$ of $1 \mathrm{M} \mathrm{Na}_{2} \mathrm{CO}_{3}$ were added, to obtain a final volume of $2 \mathrm{~mL}$. Samples were incubated at $40{ }^{\circ} \mathrm{C}$ for $30 \mathrm{~min}$. Measurements were performed in triplicate. Absorbance values were measured at $765 \mathrm{~nm}$ using a Uvicon XL spectrophotometer (BIO-TEK Instruments SAS, Colmar, France). Quantification was obtained by reporting the absorbance measured on the calibration curve of gallic acid used as a standard

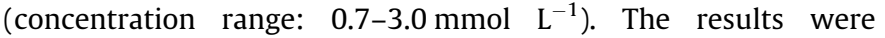
expressed in millimol of gallic acid equivalent per litre ( $\mathrm{mmol}$ $\mathrm{GAE} \mathrm{L}^{-1}$ ).

Separation and quantification of the $\mathrm{EWH}^{+}$extract compounds were carried out by HPLC with a diode array detector (DAD) on a reversed phase column Lichrospher $100 \mathrm{RP}-18$ (250×4.6 mm;
$5 \mu \mathrm{m})$ protected by a pre-column of the same phase. The oven was thermostated at $30^{\circ} \mathrm{C}$ for all tests. The injected volume was $5 \mu \mathrm{L}$. The mobile phase consisted of a linear gradient between solvent $\mathrm{A}: \mathrm{H}_{2} \mathrm{O} / \mathrm{HCO}_{2} \mathrm{H}(95: 5, \mathrm{v} / \mathrm{v})$ and solvent $\mathrm{B}: \mathrm{H}_{2} \mathrm{O} / \mathrm{HCO}_{2} \mathrm{H} / \mathrm{MeCN}$ $(15: 5: 80, v / v / v)$, from $0 \%$ solvent $B$ to $80 \%$ solvent $B$. The flow rate was $0.25 \mathrm{~mL} / \mathrm{min}$. Identification was achieved by comparison of both retention times and absorption spectra obtained for each eluted peak with those of suitable standards. Concentrations were calculated from the chromatogram peak areas with suitable external standards. Particularly, caffeic acid (commercial) and luteolinidin (chemically synthesised) were used for the quantification of phenolic acids and anthocyanidins, respectively.

\subsubsection{ORAC test}

ORAC values of $\mathrm{EWH}^{+}$-PCs and 3-DAs were measured on a Perkin-Elmer fluorescence spectrometer by inhibition of $2^{\prime}, 7^{\prime}$ dichlorofluorescein oxidation according to the method previously reported (Ishimoto et al., 2012) with slight modifications. Briefly, all samples and reagents were dissolved in $10 \mathrm{mM}$ phosphate $/ 150 \mathrm{mM}$ $\mathrm{NaCl}$ buffer (PBS) at pH 7.4; $50 \mu \mathrm{L}$ test samples or $50 \mu \mathrm{L}$ Trolox solutions $(0-20 \mu \mathrm{M}), 100 \mu \mathrm{L} 2^{\prime}, 7^{\prime}$ 'dichlorofluorescein solution (50 $\mathrm{nM})$, and $100 \mu \mathrm{L}$ AAPH solution $(20 \mathrm{mM})$ were added to the wells of a 96 -well plate. The fluorescence was recorded at $37^{\circ} \mathrm{C}$ every $1 \mathrm{~min}$ for $100 \mathrm{~min}$ at respective excitation and emission wavelengths of 485 and $535 \mathrm{~nm}$. A calibration curve was generated by using the correlation between the period of time needed to obtain $50 \%$ fluorescence decay and the Trolox concentration. ORAC levels were expressed as mole of Trolox equivalents (TE) per mole of antioxidant standard or mole of GAE (extracts). Gallic and caffeic acids were used as controls. Their respective ORAC values of $1.5 \pm 0.4$ and $5.3 \pm 0.3 \mathrm{~mol} \mathrm{TE} \mathrm{mol}^{-1}$ (means $\pm \mathrm{SEM} ; n=13$ ) were similar to those previously reported Ishimoto et al. (2012).

\subsection{LDL oxidation studies}

\subsubsection{Human LDL preparation and oxidation}

LDL was isolated from fresh human plasma obtained from the "French Blood Establishment", in accordance with ethical rules of that establishment (Cartron et al., 2001) by sequential ultracentrifugation. LDL purity was controlled by electrophoresis and was obtained without serum albumin contamination (data not shown). LDL oxidisability was monitored at $234 \mathrm{~nm}$ and $245 \mathrm{~nm}$ for $\mathrm{Cu}^{2+}$ and AAPH-induced oxidation, respectively. Isolated LDL was diluted to $1 \mu \mathrm{mol}$ apoB $\mathrm{L}^{-1}$ to investigate the antioxidant efficiency of PCs. LDL was incubated with various PC concentrations (expressed as $\mu \mathrm{mol} \mathrm{GAE} \mathrm{L}^{-1}$ for red and white sorghum PC extracts, luteolinidin and apigeninidin, for comparison, and as $\mu \mathrm{mol} \mathrm{L} \mathrm{L}^{-1}$ for all pure standard compounds), then oxidised in the presence of either $5 \mu \mathrm{M} \mathrm{Cu}^{2+}$, or $5 \mathrm{mM} \mathrm{AAPH}$ after a tenfold dilution in a pH 7.4 oxygenated PBS as previously described (Cartron et al., 2001). The kinetic peroxidation profile was principally characterised by the lag time $\left(t_{\text {lag }}\right)$ during which the accumulation of conjugated dienes is very slow. The relative $t_{\mathrm{lag}}$, defined as $r t_{\mathrm{lag}}=$ $\left(t_{\text {lag }+} / t_{\text {lag- }}\right) \times 100$, $\left(t_{\text {lag+ }}\right.$ being the $t_{\text {lag }}$ in the presence of antioxidant, $t_{\text {lag- }}$ in its absence), was then plotted $v s$. increasing concentrations of the different tested compounds, producing a linear relationship. The specific antioxidant activity (SAA) was defined as the slope of this linear relationship, as previously described Cartron et al. (2001) and was expressed as $\mu \mathrm{mol} \mathrm{GAE}{ }^{-1} \mathrm{~L}$ or as $\mu \mathrm{mol}^{-1} \mathrm{~L}$, depending on the concentration expression (Cartron et al., 2001; Monde et al., 2011).

\subsubsection{LDL-vitamin E analyses}

$\mathrm{EWH}^{+}$-PC and 3-DAs' (luteolinidin and apigeninidin) influence on the time course of in vitro LDL $\alpha$-tocopherol (Vit E) consumption 
was determined after Vit E extraction by hexane/ethyl acetate (3/1; $\mathrm{v} / \mathrm{v}$ ) from oxidized LDL. For this, we measured the extracted products by means of an HPLC method with a Lichrocart ${ }^{\circledR} 125-4(5-\mu \mathrm{m}$ particle size) column (Merck, France), with $\delta$-tocopherol as an internal standard, as previously described by us Monde et al. (2011).

\subsection{Statistical analysis}

All analyses were carried out in triplicate or more. Results are expressed as mean \pm standard deviation (SD) or standard error of the mean (SEM). Data were compared on the basis of the mean values, using Stata Software V10.0 (Stata Corp, 2007 edition). The level of significance was set at $p<0.05$.

\section{Results and discussion}

Sorghum and barley are two important dietary grains reported to contain significant quantities of phenolic compounds (Folliard, Traoré, Vaksmann, \& Kouressy, 2004). However, sorghum and its products have not been explored extensively for their phytochemical and biological effects. Epidemiological studies have clearly demonstrated that a diet containing whole grain cereals can protect against metabolic disorders, such as cardiovascular disease (Anderson, 2003), cancer (Chatenoud et al., 2012) and diabetes (Venn \& Mann, 2004). We have investigated the antioxidant properties of PCs of red and white sorghum extracts in comparison with the two 3-DAs, luteolinidin and apigeninidin, which are commonly, found in red sorghums but have a restricted distribution in nature (Awika et al., 2004).

\subsection{Chemical synthesis of 3-DAs}

4',5,7-Trihydroxyflavylium chloride (apigeninidin, [1]) and $3^{\prime}, 4^{\prime}, 5,7$-tetrahydroxyflavylium chloride (luteolinidin, [2]) could be extracted and purified from sorghum in small amounts and time- and solvent-consuming procedures or obtained at a high cost from commercial sources. As an alternative, in this work, [1] and [2] were efficiently synthesised, according to an essentially twostep route (Fig. 1) that is much simpler than the previously reported procedure (Sweeny \& Iacobucci, 1981). First, 2,4,6-trihydroxybenzaldehyde has to be converted into 2,4-diacetoxy-6hydroxy-benzaldehyde, not only to ensure solubility in EtOAc (the most convenient solvent for the subsequent condensation step) but also to deactivate the substrate toward oligomerisation (via acid-catalysed aromatic electrophilic substitution) leading to unidentified red pigments. This strategy was already applied to the synthesis of a natural anthocyanin (Dangles, \& El Hajji, 1994). However, to our knowledge, this is the first time that the chemical synthesis of [1] and [2] is reported in detail. The satisfying yield and regioselectivity of the acylation step may be attributed to the strong hydrogen bond between the carbonyl group and one of the adjacent $\mathrm{OH}$ groups, which is thus relatively nonreactive. The flavylium chromophore was constructed via acid-catalysed aldol condensation followed by cyclisation and subsequent dehydration. Flavylium chlorides thus formed precipitated and were therefore easily isolated for subsequent deacetylation by sodium methylate. Re-acidification and purification on reversed-phase silica afforded pure pigments [1] and [2]. The ${ }^{1} \mathrm{H}$ - and ${ }^{13} \mathrm{C}-\mathrm{NMR}$ spectra of [1] were in agreement with the literature (Kouda-Bonafos, Narco, \& Ancian, 1996). The NMR data of [2] were consistent with those of already reported analogues (Bjoroy, Rayyan, Fossen, Kalberg, \& Anderson, 2009; Dangles \& El Hajji, 1994; El Hajji, Dangles, Figueiredo, \& Brouillard, 1997).

\subsection{Polyphenol extraction, quantification and antioxidant activity}

Phenolic content of Côte d'Ivoire's sorghum varieties were evaluated as $3.90 \pm 0.01$ and $0.07 \pm 0.01 \mathrm{mmol} \mathrm{GAE} \mathrm{L}^{-1}$ in $\mathrm{EWH}^{+}$-PCs of red and white sorghums, respectively. They were also expressed in whole flour as $9.1 \pm 0.9$ and $0.17 \pm 0.02 \mathrm{mg} \mathrm{GAE} \mathrm{g}^{-1}$ on a dry matter basis, under our experimental extraction conditions. Moreover, $1 \mathrm{~mol}$ of apigeninidin [1] and $1 \mathrm{~mol}$ of luteolinidin [2] are equivalent to $1.06 \pm 0.03$ and $1.96 \pm 0.12 \mathrm{~mol} \mathrm{GAE}$, respectively; and $1 \mathrm{~mol}$ of $[\mathbf{1}+2]$ is equivalent to $1.35 \pm 0.01 \mathrm{~mol} \mathrm{GAE}(n=5)$.

The major polyphenolic compounds were analysed by HPLCDAD (Fig. 2) and presented in Table 1. As shown in Fig. 2C, red sorghum contains 3-DAs (luteolinidin and apigeninidin) and some derivatives (mono-, di-methyl ethers and unidentified glycosides). However, white sorghum does not contain 3-DAs nor flavanols (catechin and epicatechin) (data not shown). The 3-DA content is not so high in the red sorghum extract $(6.5 \%$ of total phenols for luteolinidin and its methylated derivatives, $2.2 \%$ for apigeninidin and its methylated derivatives), while flavanols and quercetin derivatives are major compounds, as shown in Table 1. Stilbenoids trans-piceid and trans-resveratrol previously quantified as low as $0.2-1 \mu \mathrm{g} \mathrm{g}^{-1}$ in red sorghum grains (Bröhan, Jerkovic, \& Collin, 2011) were not looked for in our study.

To evaluate the antioxidant capacity of sorghum polyphenol extracts, we firstly determined their oxygen radical absorbing capacity (ORAC) in comparison with pure synthetic 3-DAs. Luteolinidin [2] and apigeninidin [1], with ORAC values of $4.9 \pm 0.4$ and $4.3 \pm 0.3 \mathrm{~mol} \mathrm{TE} \mathrm{mol}^{-1}$, respectively, were in the same range as potent flavonoids (e.g., quercetin and myricetin) but less potent than catechin or epicatechin, which show remarkable ORAC levels (Ishimoto et al., 2012). Moreover, an equimolar addition of the two compounds $[\mathbf{1}+\mathbf{2}]$ gave an ORAC value $(4.7 \pm 0.3 \mathrm{~mol} \mathrm{TE}$ $\mathrm{mol}^{-1}$ ) equivalent to that of each of the compounds taken in isolation, without any synergy. All these results are expressed as mean$\mathrm{S} \pm \operatorname{SEM}(n=5-8)$. While devoid of a catechol group, apigeninidin is only slightly less potent than luteolinidin. This is unexpected, as the catechol group is typically put forward as the major determinant of the radical-scavenging capacity, owing to the relative stability of the corresponding semiquinone radical (Dangles, 2012).

As expected, $1 \mathrm{~g}$ of red sorghum is much more effective ( $c a$. a factor 25) at scavenging peroxyl radicals than the same amount of white sorghum (ORAC values $=103.8 \pm 2.1 \mu \mathrm{mol} \mathrm{TE} \mathrm{g}^{-1}$ and $4.2 \pm 0.2 \mathrm{~mol} \mathrm{TE}^{-1}$; respectively). However, this gain in efficiency is lower than what could be anticipated from the richness of PCs in red sorghum (a factor $\mathrm{ca} .54$ in comparison with white sorghum based on the Folin-Ciocalteu test). Hence, when data are expressed in terms of GAE (instead of dry mass), the red sorghum $\mathrm{EWH}^{+}-\mathrm{PC}$ extract with an ORAC value of $1.93 \pm 0.04 \mathrm{~mol} \mathrm{TE} \mathrm{mol} \mathrm{GAE}^{-1}$ came up as less effective than the white sorghum $\mathrm{EWH}^{+}-\mathrm{PC}$ extract ( ORAC value $=4.32 \pm 0.15 \mathrm{~mol}$ TE mol GAE ${ }^{-1}$ ) and the two pure 3-DAs. This suggests that, although poor in polyphenols, white sorghum contains other antioxidants that could be intrinsically more potent at scavenging peroxyl radicals than those of red sorghum. In other words, for a fixed concentration expressed in $\mu \mathrm{mol} \mathrm{GAE} \mathrm{L}^{-1}$, i.e. for a given capacity at reducing $\mathrm{Mo}^{\mathrm{VI}}$ (the basis of the Folin-Ciocalteu test), antioxidants from white sorghum are better peroxyl radical scavengers (the basis of the ORAC test) than those extracted from red sorghum.

Finally, on a whole flour dry weight basis, $\mathrm{EWH}^{+}$-PCs of red sorghum displayed ORAC activities in the range of those previously found for different sorghum varieties (Awika et al., 2009; Bröhan et al., 2011), showing that the EWH ${ }^{+}$-PC extraction method used in this study was as efficient as other extraction techniques previously used for easily extractable (loosely bound) compounds, e.g., $1 \% \mathrm{HCl} /$ methanol (Awika et al., 2009), or acetone/water (7/3) (Bröhan et al., 2011). 


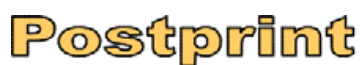

Version définitive du manuscrit publiée dans / Final version of the manuscript published in :

Food Chemistry (2014), Vol. 145, p. 701-709, DOI: 10.1016/j.foodchem.2013.07.025

Journal homepage: www.elsevier.com/locate/foodchem

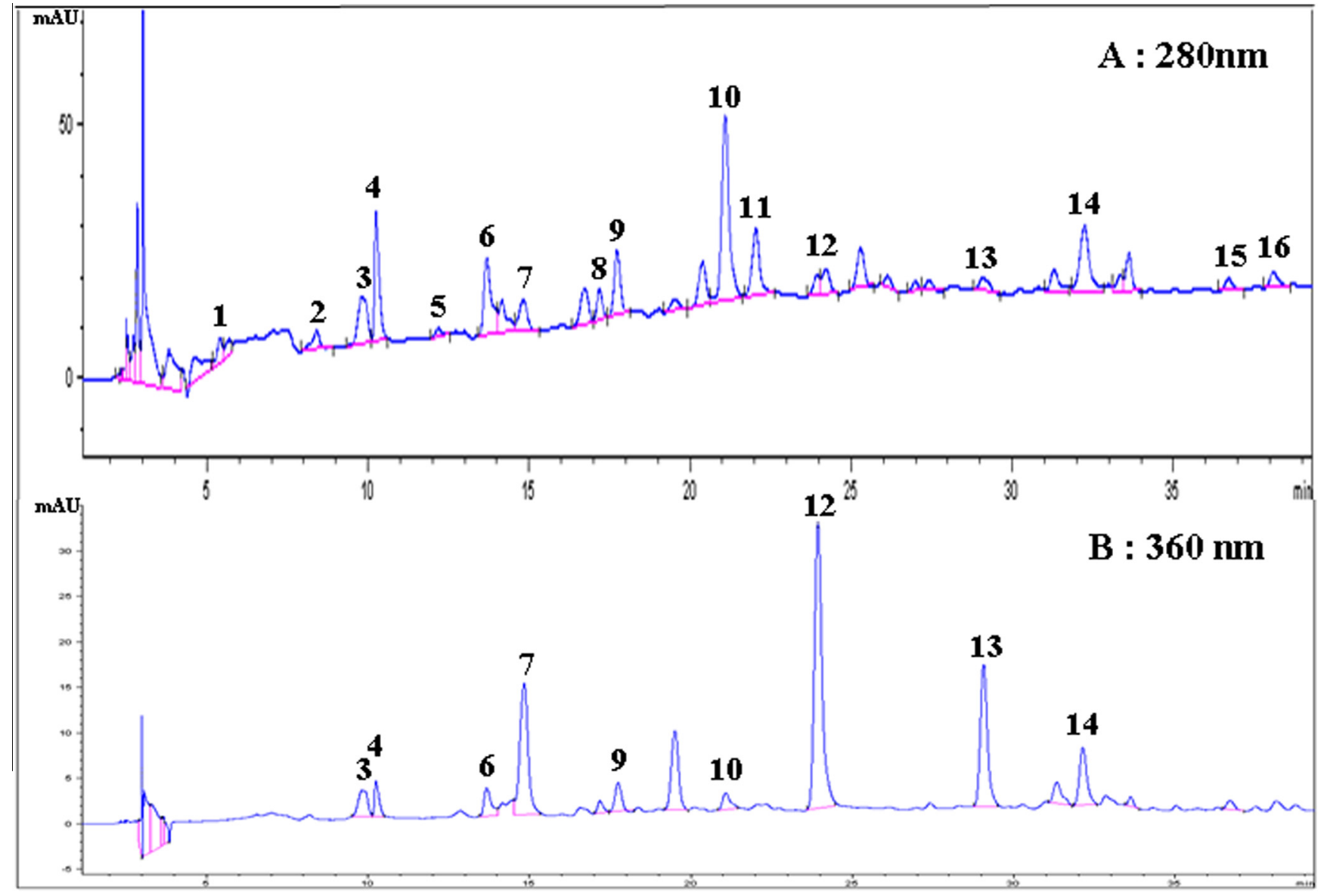

Time (min)

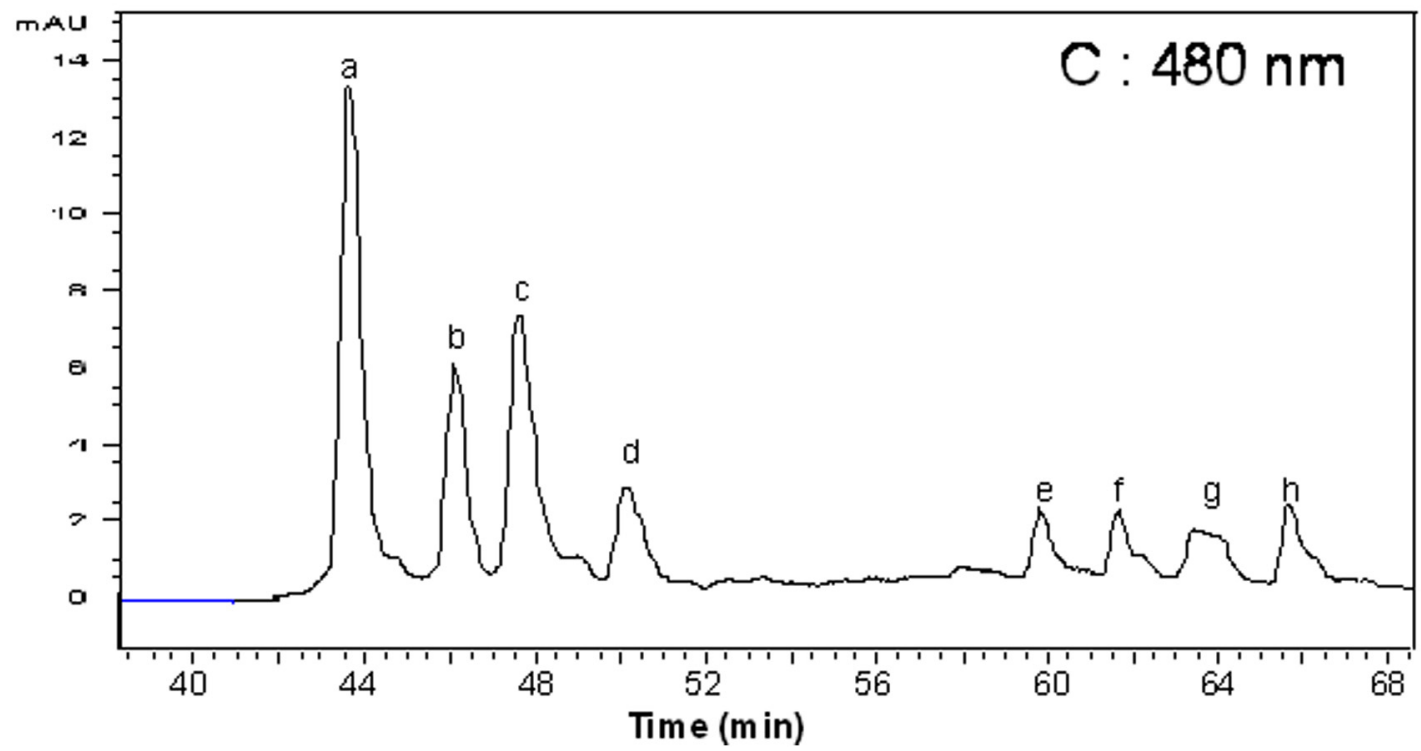

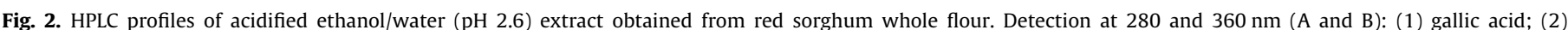

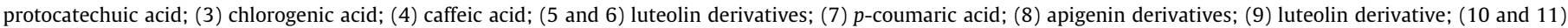

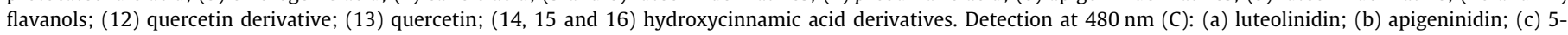

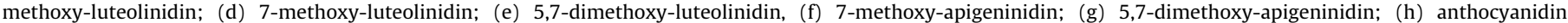
derivatives. 
Version définitive du manuscrit publiée dans / Final version of the manuscript published in :

Food Chemistry (2014), Vol. 145, p. 701-709, DOI: 10.1016/j.foodchem.2013.07.025

Journal homepage: www.elsevier.com/locate/foodchem

Table 1

Main polyphenolic compounds of $\mathrm{EWH}^{+}$extracts from red and white sorghum whole flour of common Côte d'Ivoire varieties.

\begin{tabular}{|c|c|c|c|c|}
\hline$t_{\mathrm{R}}(\min )$ & Phenolic compounds & $\lambda(\mathrm{nm})$ & Red sorghum $\mu \mathrm{g} \mathrm{g}^{-1}$ dry weight & White sorghum $\mu \mathrm{g} \mathrm{g}^{-1}$ dry weight \\
\hline 5.4 & Gallic acid & 280 & 2.0 & 1.2 \\
\hline 8.4 & Protocatechuic acid & 280 & 5.3 & 3.2 \\
\hline 9.8 & Chlorogenic acid & 330 & 10.5 & 3.6 \\
\hline 10.2 & Caffeic acid & 330 & 10.0 & 3.1 \\
\hline 14.8 & p-Coumaric acid & 330 & 6.8 & 2.0 \\
\hline $21.0,22.0$ & Flavanols & 280 & 266.8 & 1.1 \\
\hline 23.029 .0 & Quercetin derivative* Quercetin & 360 & 74.3 & 1.1 \\
\hline 44.6 to 61.3 & Luteolinidin + derivatives ${ }^{* *}$ & 480 & 26.5 & - \\
\hline 46.9 to 65.1 & Apigeninidin + derivatives ${ }^{* *}$ & 480 & 9.0 & - \\
\hline
\end{tabular}

Results are reported as the means of two separate analyses.

$t_{\mathrm{R}}=$ retention time.

Unidentified glycoside.

Mono- and dimethyl ethers.

Table 2

Antioxidant effects of red and white sorghum EWH'+PCs and 3-DAs in comparison with some standard phenolic acids or flavonoids, assessed by in vitro LDL oxidation.

\begin{tabular}{|c|c|c|}
\hline & $\mathrm{Cu}^{2+}$-induced oxidation SAA; $n(r)$ & AAPH-induced oxidation SAA; $n(r)$ \\
\hline Red sorghum ${ }^{\mathrm{a}}$ & $163.0 ; 13\left(0.95^{* *}\right)$ & $46.5 ; 10\left(0.97^{* *}\right)$ \\
\hline White sorghum ${ }^{\mathrm{b}}$ & $97.0 ; 13\left(0.97^{* *}\right)$ & $39.0 ; 12\left(0.96^{* *}\right)$ \\
\hline Luteolinidin ${ }^{c}$ & $67.0 / 131.4 ; 12\left(0.96^{* *}\right)$ & $19.3 / 37.8 ; 10\left(0.95^{* *}\right)$ \\
\hline Apigeninidin $^{d}$ & $19.7 / \underline{20.7} ; 12\left(0.67^{*}\right)$ & $-2.7 /-2.8 ; 10\left(0.64^{*}\right)$ \\
\hline Luteolinidin + Apigeninidin & $74.0 / 100.0 ; 12\left(0.99^{* *}\right)$ & $19.7 / 26.6 ; 10\left(0.91^{* *}\right)$ \\
\hline Caffeic acid ${ }^{\mathrm{e}}$ & $54.0 ; 24\left(0.76^{*}\right)$ & $73.6 ; 8\left(0.99^{* *}\right)$ \\
\hline Chlorogenic acid ${ }^{\mathrm{e}}$ & $155.5 ; 8\left(0.99^{* *}\right)$ & $\underline{55.3} ; 12\left(0.98^{* *}\right)$ \\
\hline Catechin $^{\mathrm{e}}$ & $34.6 ; 15\left(0.91^{* *}\right)$ & $156.2 ; 10\left(0.99^{* *}\right)$ \\
\hline Quercetin & $216.8 ; 18\left(0.92^{* *}\right)$ & - \\
\hline Rutin $^{f}$ & $187.8 ; 10\left(0.94^{* *}\right)$ & $\underline{82.6} ; 10\left(0.99^{* *}\right)$ \\
\hline
\end{tabular}

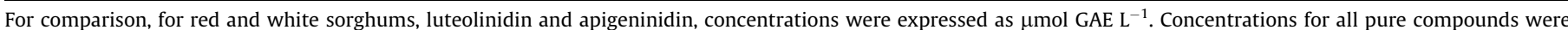
expressed in $\mu \mathrm{mol} \mathrm{L}{ }^{-1}$.

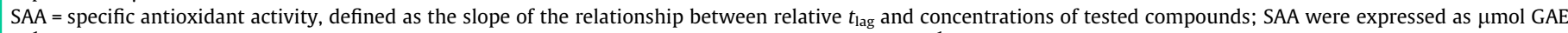
$\mathrm{L}^{-1}$ for red and white sorghums, luteolinidin and apigeninidin (non-underlined values) and as $\mu \mathrm{mol}^{-1} \mathrm{~L}$ for all pure compounds, (underlined values).

$n=$ Number of independent measures; $r=$ correlation coefficient; ${ }^{* *} p<0.01 ;{ }^{*} p<0.05$.

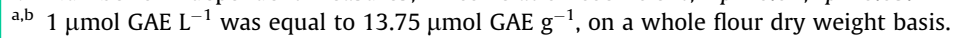

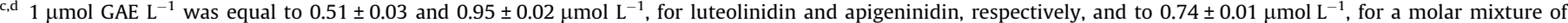
luteolinidin + apigeninidin.

e,f Previously shown by our team (Cartron et al., 2001 and Monde et al., 2011; respectively).

\subsection{Polyphenol protective effect on human LDL oxidisability}

The inhibition of $\mathrm{Cu}^{2+}$ - or AAPH-induced human LDL oxidation was then investigated in vitro at different concentrations of red and white sorghum $\mathrm{EWH}^{+}$-PC and of luteolinidin and apigeninidin. In both oxidation protocols, the concentrations of sorghum ex-

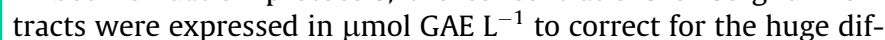
ference in phenolic content between red and white sorghum. During both $\mathrm{Cu} 2+-$ and AAPH-induced LDL oxidation in the presence of red and white sorghum EWH+-PCs, $t_{\text {lag }}$ values increase with increasing PC concentrations, as previously shown by our team for other PCs (Cartron et al., 2001; Monde et al., 2011). Moreover, during the propagation phase of conjugated diene $(\mathrm{CD})$ production, the oxidation rate $R_{\mathrm{p}}(\mathrm{CD})$ slightly decreased in $\mathrm{Cu}^{2+}$-mediated oxidation only for red sorghum $\mathrm{EWH}^{+}$-PCs. To confirm this result, a significant linear correlation was obtained by plotting the logarithm of $R_{\mathrm{p}}(\mathrm{CD})^{+} / R_{\mathrm{p}}(\mathrm{CD})^{-} v s$. the logarithm of $t_{\text {lag+ }+} / t_{\text {lag- }}$ (data not shown).

From the SAA values, in the metal-dependent oxidation (Table 2), the order of antioxidant efficiency is: red sorghum $>$ white sorghum > luteolinidin [2] > apigeninidin [1]. The antioxidant activity of an equimolar mixture of [1] and [2] is almost equal to that of [2] alone and is much lower than that of the red sorghum $\mathrm{EWH}^{+}-\mathrm{PCs}$. When pure compounds are compared (concentrations expressed in $\mu \mathrm{mol} \mathrm{L}^{-1}$ ), chlorogenic acid, quercetin and rutin appear to be the best inhibitors of the copper-induced LDL oxidation. This observation suggests that the last three phenolic compounds most strongly interact with copper ions and/or copper-binding sites on LDL (chlorogenic acid possibly via its quinic moiety since caffeic acid is much less efficient). Owing to its catechol nucleus, the critical determinant of metal chelation and radical-scavenging capacity (Dangles, 2012; Yeomans, Linseisen, \& Wolfram, 2005), luteolinidin is fairly active, although slightly less than chlorogenic acid and the two flavonols, whereas apigeninidin (no catechol nucleus) is weakly active. However, although luteolinidin is probably a much better metal chelator than apigeninidin, the ORAC test suggests that it may not be that much more efficient at scavenging peroxyl radicals. Finally, on the basis of the SAA values obtained, the observation that the red sorghum $\mathrm{EWH}^{+}$-PCs are better inhibitors of LDL oxidation than white sorghum $\mathrm{EWH}^{+}$-PCs and both individual 3-DA components may be interpreted as follows: (a) red sorghum contains other efficient phenolic antioxidants also present in the white variety but in very low concentrations (Table 1); and/or (b) efficient synergisms could take place between some red sorghum phenolic compounds.

The data of AAPH-induced LDL oxidation largely confirm those of the copper-induced process. Luteolinidin is an average inhibitor typically less potent than common polyphenols having a catechol nucleus. Surprisingly, apigeninidin even displays a weak pro-oxidant activity, as evidenced by a small negative SAA value. Catechin and, to a lesser extent, rutin are the most effective free radical scavengers in this system.

To understand the observed protective effect of these polyphenols, their influence on the time course of LDL-vitamin E (Vit E) consumption under $\mathrm{Cu}^{2+}$-mediated oxidation was investigated as 
Version définitive du manuscrit publiée dans / Final version of the manuscript published in :

Food Chemistry (2014), Vol. 145, p. 701-709, DOI: 10.1016/j.foodchem.2013.07.025

Journal homepage: www.elsevier.com/locate/foodchem

shown in Fig. 3 for red sorghum EWH ${ }^{+}$-PCs, in parallel with CD production. Comparable kinetic curves were obtained for luteolinidin and apigeninidin, individually or in combination, and for white sorghum EWH ${ }^{+}$-PCs (figures not shown). As shown in Table 3, Vit E consumption and $\mathrm{CD}$ production are delayed in a dose-dependent manner by the different EWH ${ }^{+}$-PCs. Firstly, initial Vit E oxidation rate $R_{\mathrm{i}}(\mathrm{VitE})$ is about twice lower when PC concentration is twice higher, pointing out a direct protection of Vit $\mathrm{E}$ by EWH ${ }^{+}-\mathrm{PCs}$. However, the very beginning of the $\mathrm{CD}$ propagation phase (i.e., the end of the inhibition period corresponding to the starting time $t_{\text {lag }}$ of detectable $\mathrm{CD}$ production) does not coincide with the period of time required for total Vit E oxidation $t_{\mathrm{vitE}}$ for $\mathrm{EWH}^{+}-\mathrm{PCs}$ and 3DAs. Unlike white sorghum EWH ${ }^{+}$-PCs for which $t_{\mathrm{vitE}} \approx t_{\text {lag }}$ (Table 3), red sorghum EWH+-PCs and 3-DAs still protect LDL from oxidation after complete consumption of Vit $\mathrm{E}$. The most efficient antioxidant is the red sorghum $\mathrm{EWH}^{+}$-PC extract, which is able to reduce significantly $(p<0.05)$ Vit $\mathrm{E}$ consumption from $R_{\mathrm{i}}(\mathrm{VitE})=$ 0.46-0.08 $\mu \mathrm{mol} \mathrm{L}^{-1} \mathrm{~min}^{-1}$ at a concentration of $4 \mu \mathrm{mol} \mathrm{GAE} \mathrm{L}{ }^{-1}$,

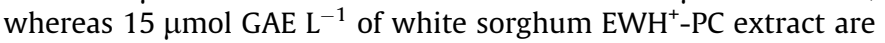
required for the same protection (Table 3). Moreover, the LDL-Vit E protection afforded by red sorghum $\mathrm{EWH}^{+}-\mathrm{PCs}$ is significantly higher than that of the luteolinidin and apigeninidin mixture $\left(R_{\mathrm{i}}(-\right.$

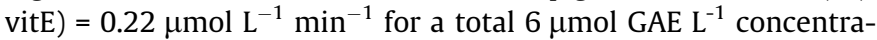
tion of DAs) (Table 3).

LDL oxidation is a complex, multistep mechanism involving both lipid and protein fractions (Pinchuk, Gal, \& Lichtenberg, 2001). In particular, AAPH-derived peroxyl radicals and lipid oxyl radicals produced by copper-induced decomposition of lipid hydroperoxide traces trigger the typical free radical chain reaction of lipid peroxidation. The effectiveness of antioxidants at inhibiting LDL peroxidation mainly depends on their diffusion to either lipid or protein fractions, their capacity to directly reduce lipid oxyl and peroxyl radicals, their affinity for transition metal ions including $\mathrm{Cu}^{2+}$ (formation of inert metal-antioxidant complexes), their capacity to regenerate endogenous antioxidants such as $\alpha$-tocopherol (vitamin E), and the fate of the antioxidant-derived aryloxyl radicals.

Red sorghum EWH+-PCs and 3-DAs not only protect vitamin E but also protect LDL after consumption of vitamin $\mathrm{E}$. This suggests that red sorghum polyphenols are first able to inhibit the onset of LDL oxidation by chelation of copper ions and possibly by partial regeneration of vitamin $\mathrm{E}$ (although no lag phase in vitamin $\mathrm{E}$

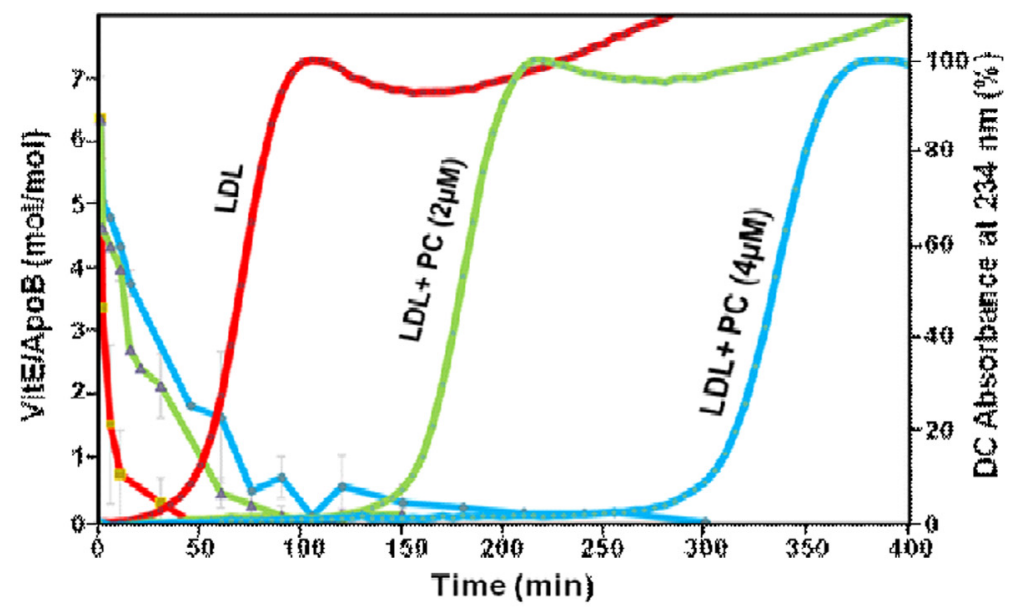

Reproduced in color on the Web and in black-and-white in print

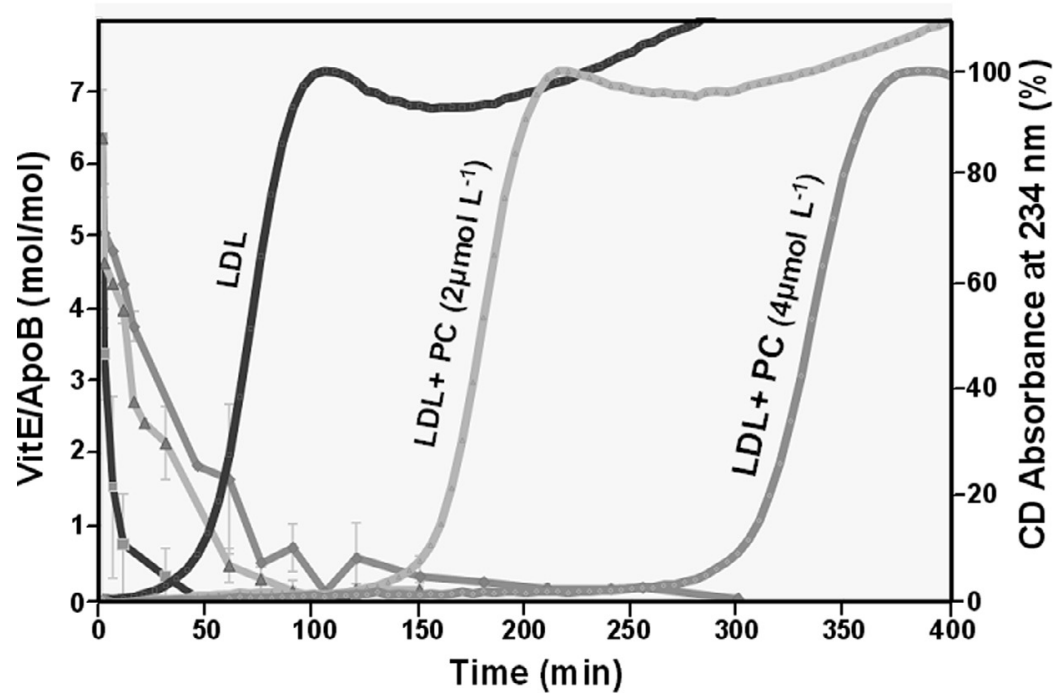

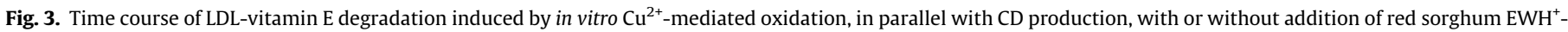

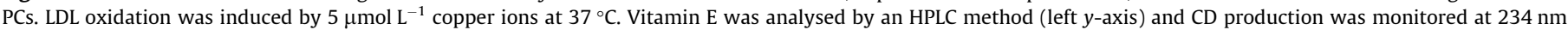

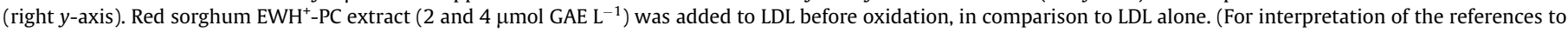
colour in this figure legend, the reader is referred to the web version of this article.) 
Version définitive du manuscrit publiée dans / Final version of the manuscript published in :

Food Chemistry (2014), Vol. 145, p. 701-709, DOI: 10.1016/j.foodchem.2013.07.025

Journal homepage: www.elsevier.com/locate/foodchem

Table 3

$\mathrm{EWH}^{+}$-PC effects of red (RSO) and white (WSO) sorghums and of 3-DAs (luteolinidin and apigeninidin) on Cu ${ }^{2+}$-mediated LDL peroxidation.

\begin{tabular}{|c|c|c|c|c|}
\hline & $\begin{array}{l}\text { Vitamin E oxidation } \\
R_{\mathrm{i}}\left(\text { Vit E) }\left(\mu \mathrm{mol} \mathrm{L}^{-1} \mathrm{~min}^{-1}\right)\right.\end{array}$ & $t_{V i t E}(\min )$ & $\begin{array}{l}\text { Conjugated diene production } \\
R_{\mathrm{p}}(\mathrm{CD})\left(\mu \mathrm{mol} \mathrm{L}^{-1} \mathrm{~min}^{-1}\right)\end{array}$ & $t_{\operatorname{lag}}(\min )$ \\
\hline LDL without PC; $n=5$ & $0.46 \pm 0.02$ & $31.0 \pm 8.0$ & $8.3 \pm 0.8$ & $39.3 \pm 7.2$ \\
\hline LDL with RSO $2 \mu \mathrm{mol} \mathrm{GAE} \mathrm{L}{ }^{-1} ; n=3$ & $0.11 \pm 0.01^{*}$ & $41.7 \pm 11.2^{*}$ & $6.4 \pm 0.1^{*}$ & $93.6 \pm 11.2^{*}$ \\
\hline LDL with RSO $4 \mu \mathrm{mol} \mathrm{GAE} \mathrm{L}{ }^{-1} ; n=3$ & $0.08 \pm 0.01^{*}$ & $85.7 \pm 4.2^{*}$ & $6.0 \pm 0.7^{*}$ & $225.5 \pm 13.6^{*}$ \\
\hline 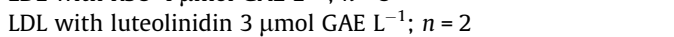 & $0.28 \pm 0.01^{*}$ & $72.5 \pm 2.5^{*}$ & $8.4 \pm 1.1$ & $101.4 \pm 9.0^{*}$ \\
\hline LDL with apigeninidin $3 \mu \mathrm{mol} \mathrm{GAE} \mathrm{L}{ }^{-1} ; n=2$ & $0.47 \pm 0.06$ & $35.0 \pm 5.0$ & $8.5 \pm 0.5$ & $57.1 \pm 2.3^{*}$ \\
\hline LDL with luteolinidin + apigeninidin $3+3 \mu \mathrm{mol} \mathrm{GAE} \mathrm{L}{ }^{-1} ; n=4$ & $0.22 \pm 0.01^{*}$ & $115.0 \pm 25.5^{*}$ & $7.4 \pm 0.9$ & $172.3 \pm 25.0^{*}$ \\
\hline LDL with WSO $5 \mu \mathrm{mol} \mathrm{GAE} \mathrm{L} \mathrm{L}^{-1} ; n=2$ & $0.27 \pm 0.01^{*}$ & $45.5 \pm 0.5^{*}$ & $7.9 \pm 0.4$ & $49.0 \pm 4.2^{*}$ \\
\hline LDL with WSO $10 \mu \mathrm{mol} \mathrm{GAE} \mathrm{L}{ }^{-1} ; n=3$ & $0.15 \pm 0.01^{*}$ & $60.3 \pm 0.5^{*}$ & $7.1 \pm 0.9$ & $58.7 \pm 12.8^{*}$ \\
\hline LDL with WSO $15 \mu \mathrm{mol} \mathrm{GAE} \mathrm{L} \mathrm{L}^{-1} ; n=3$ & $0.08 \pm 0.03^{*}$ & $94.8 \pm 7.0^{*}$ & $6.2 \pm 1.0^{*}$ & $79.8 \pm 12.8 *$ \\
\hline
\end{tabular}

$n=$ Number of independent experiments.

Significant values $(p<0.05)$ compared with the value obtained for LDL without phenolic compounds.

consumption is observed; see Fig. 3). After vitamin E consumption, red sorghum polyphenols and/or some of their oxidation products liable to diffuse into the core of the LDL particles, could prolong the lag phase of $\mathrm{CD}$ production by a direct scavenging of the propagating lipid peroxyl radicals.

As suggested by the pro-oxidant activity of apigeninidin in AAPH-induced LDL oxidation, the aryloxyl radicals formed from apigeninidin may be reactive enough to re-initiate lipid peroxidation by $\mathrm{H}$-atom abstraction from PUFA moieties, as already evidenced in $\boldsymbol{\alpha}$-tocopherol mediated LDL peroxidation (Litwinienko \& Ingold, 2007). It is also known that the flavone apigenin promotes superoxide formation in the peroxidase-catalysed oxidation of glutathione (GSH) by $\mathrm{H}_{2} \mathrm{O}_{2}$ whereas luteolin is inhibitory. In the first case, apigenin aryloxyl radicals are reactive enough to abstract the thiol $\mathrm{H}$-atom of GSH, thereby inducing a cascade leading to $\mathrm{O}_{2}$ reduction. In the second case, the luteolin semiquinone is rapidly oxidised to the $o$-quinone, which simply undergoes conjugation with GSH (Galati, Moridani, Chan, \& O’Brien, 2001).

It must also be kept in mind that in neutral conditions 3-DAs are actually a mixture of coloured quinonoid bases and colourless chalcones, formed from flavylium ions by deprotonation and water addition, respectively (Pina, Melo, Laia, Parola, \& Lima, 2012). Those forms may partition differently between the aqueous, protein and lipid phases, thereby further complicating the interpretations.

This complexity in interpreting the inhibition of LDL oxidation could explain why EWH ${ }^{+}$-PCs of red sorghum afford a more potent protection against LDL oxidation than pure 3-DAs, while 3-DAs are more efficient than $\mathrm{EWH}^{+}$-PCs of red sorghum in the ORAC test, where the sole operating mechanism is $\mathrm{H}$-atom transfer reactions from the phenols to AAPH-derived peroxyl radicals. The low correlation between the inhibition of LDL oxidation and ORAC test by the sorghum polyphenols suggests that, when PCs are screened for their antioxidant activity, more realistic structured models involving lipids and proteins should be preferred to the ORAC assay.

It is now well known that a flavonoid-rich diet (onion, cereals) or beverages (green and black tea, wine) permits the detection of low concentrations of flavonoid metabolites in the plasma, thus confirming their partial bioavailability (Cartron et al., 2003; Crozier, Jaganath, B.\& Clifford, \& M. N., 2009). However, these metabolites could also exhibit non antioxidant (e.g., anti-inflammatory) effects in relation with the prevention of chronic diseases (Halliwell, Rafter, \& Jenner, 2005). Particularly, PCs that are able to delay the in vitro LDL-vitamin E oxidation (Cartron et al., 2001; Monde et al., 2011) could as well exert direct in vivo beneficial antioxidant effects within the oesophageal (Awika et al., 2009) and gastrointestinal tracts by protecting dietary polyunsaturated lipids and vitamin $\mathrm{E}$ and/or by scavenging potential carcinogens. It is perhaps on this aspect that more investigations on the biological activity of dietary polyphenols should focus in the future.

\section{Conclusion}

In this study, we have investigated the composition of easily extractable polyphenolic compounds of red and white sorghum whole flour from Côte d'Ivoire, in order to determine their antioxidant activities in comparison to synthesised 3-DAs, luteolinidin and apigeninidin. The results of our study show that the sorghum extracts possess a significant free radical-scavenging activity (ORAC test). For a given phenolic concentration (expressed in $\mu \mathrm{mol}$ $\mathrm{GAE} \mathrm{L}^{-1}$ ), white sorghum could even be more potent than red sorghum. However, when a more physiological test was used (LDL oxidisability), the red sorghum extract came up as more efficient than white sorghum and 3-DAs. Its effectiveness is of the order of the potent inhibitors of LDL oxidation quercetin and its 3-O-glycoside rutin. When PCs are screened for their antioxidant activity, more realistic structured models involving lipids and proteins should be preferred to the ORAC assay.

Polyphenols in plants can be classified as easily extractable (loosely bound) or poorly extractable (strongly bound). Recent investigations have demonstrated that the polyphenolic content of plant foods is often underestimated because significant amounts remain in the extraction residues and thus escape quantification (Durazzo, Turfani, Azzini, Maiani, \& Carcea, 2013). It could also be interesting to evaluate the antioxidant activity of poorly extractable (strongly bound) PCs that could be present in red sorghum whole flour.

\section{References}

Anderson, J. W. (2003). Whole grains protect against atherosclerotic cardiovascular disease. Proceedings of the Nutrition Society, 62, 135-142.

Awika, J. M., Rooney, L. W., \& Waniska, R. D. (2004). Anthocyanins from black sorghum and their antioxidant properties. Food Chemistry, 90, 293-301.

Awika, J. M., Yang, L., Browning, J. D., \& Faraj, A. (2009). Comparative antioxidant, antiproliferative and phase II enzyme inducing potential of sorghum (Sorghum bicolor) varieties. LWT -. Food Science and Technology, 42, 1041-1046.

Bjoroy, O., Rayyan, S., Fossen, T., Kalberg, K., \& Andersen, O. M. (2009). C-glycosylanthocyanidins synthesized from C-glycosylflavones. Phytochemistry, 70, 278-287.

Bröhan, M., Jerkovic, V., \& Collin, S. (2011). Potentiality of red sorghum for producing stilbenoid-enriched beers with high antioxidant activity. Journal of Agricultural and Food Chemistry, 59, 4088-4094.

Cartron, E., Carbonneau, M. A., Fouret, G., Descomps, B., \& Léger, C. L. (2001). Specific antioxidant activity of caffeoyl derivatives and other natural phenolic compounds: LDL protection against oxidation and decrease in the proinflammatory lysophosphatidylcholine production. Journal of Natural Products, 64, 480-486.

Cartron, E., Fouret, G., Carbonneau, M. A., Lauret, C., Michel, F., Monnier, L., et al (2003). Red-wine beneficial long-term effect on lipids but not on antioxidant characteristics in plasma in a study comparing three types of wine-description of two $\mathrm{O}$-methylated derivatives of gallic acid in humans. Free Radical Research 37, 1021-1035.

Chatenoud, L., Tavani, A., La Vecchia, C., Jacobs, D. R., Jr., Negri, E., Levi, F., et al. (2012). Whole grain food intake and cancer risk. International Journal of Cancer, 77, 24-28. 
Version définitive du manuscrit publiée dans / Final version of the manuscript published in :

Food Chemistry (2014), Vol. 145, p. 701-709, DOI: 10.1016/j.foodchem.2013.07.025

Journal homepage: www.elsevier.com/locate/foodchem

Crozier, A., Jaganath, I., \& Clifford, M. N. (2009). Dietary phenolics: chemistry, bioavailability and effects on health. Natural Products Reports, 26, 1001-1043.

Dangles, O. (2012). Antioxidant activity of plant phenols: chemical mechanisms and biological significance. Current Organic Chemistry, 16, 692-714.

Dangles, O., \& El Hajji, H. (1994). Synthesis of 3-methoxy- and 3-( $\beta$-D-glucopyranosyloxy) flavylium ions. Influence of the flavylium substitution pattern on the reactivity of anthocyanins in aqueous solution. Helvetica Chimica Acta, 77, $1595-1610$.

Durazzo, A., Turfani, V., Azzini, E., Maiani, G., \& Carcea, M. (2013). Phenols, lignans and antioxidant properties of legume and sweet chestnut flours. Food Chem., 140, 666-671.

El Hajji, H., Dangles, O., Figueiredo, P., \& Brouillard, R. (1997). 3'-( $\beta$-D-Glycopyranosyloxy)flavylium ions: synthesis and investigation of their properties in aqueous solution. Hydrogen bonding as a mean of colour variation. Helvetica Chimica Acta, 80, 398-413.

Folliard, A., Traoré, P. C. S., Vaksmann, M., \& Kouressy, M. (2004). Modeling of sorghum response to photoperiod: a threshold-hyperbolic approach. Field Crops Research, 89, 59-70.

Galati, G., Moridani, M. Y. Chan, T. S., \& O'Brien, P. J. (2001). Peroxidative metabolism of apigenin and naringenin versus luteolin and quercetin: glutathione oxidation and conjugation. Free Radical Biology \& Medicine, 30, 370-382.

Halliwell, B., Rafter, J., \& Jenner, A. (2005). Health promotion by flavonoids, tocopherols, tocotrienols, and other phenols: direct or indirect effects? Antioxidant or not? American Journal of Clinical Nutrition, 81(suppl), 268S-276S.

Isaacson, C (2005). The change of the staple diet of black South Africans from sorghum to maize (corn) is the cause of the epidemic of squanous carcinoma of the esophagus. Medical Hypotheses, 64, 658-660.

Ishimoto, H., Tai, A., Yoshimura, M., Amakura, Y., Yoshida, T., Hatano, T., et al. (2012) Antioxidative properties of functional polyphenols and their metabolites assessed by an ORAC assay. Bioscience Biotechnology and Biochemistry, 76, 395-399.

Kouda-Bonafos, M., Narco, M., \& Ancian, B. (1996). Total assignment of ${ }^{1} \mathrm{H}$ and ${ }^{13} \mathrm{C}$ NMR chemical shifts of a natural anthocyanidin, apigeninidin, using two- dimensional COLOC and HMBC techniques. Magnetic Resonance in Chemistry, 34, 389-394.

Litwinienko, G., \& Ingold, K. U. (2007). Solvent effects on the rates and mechanisms of reaction of phenols with free radicals. Accounts of Chemical Research, 40, 203-222.

Monde, A., Carbonneau, M. A., Michel, F., Lauret, C., Diabate, S., Konan, E., et al. (2011). Potential health implication of in vitro human low-density lipoproteinvitamin E oxidation modulation by polyphenols derived from Côte d'Ivoire's oil palm species. Journal of Agricultural and Food Chemistry, 59, 9166-9171.

Pina, F., Melo, M. J., Laia, C. A. T., Parola, A. J., \& Lima, J. C. (2012). Chemistry and applications of flavylium compounds: a handful of colours. Chemical Society Reviews, 41, 869-908.

Pinchuk, I., Gal, S., \& Lichtenberg, D. (2001). The dose-dependent effect of copperchelating agents on the kinetics of peroxidation of low-density lipoprotein (LDL). Free Radical Research, 34, 349-362.

Sweeny, J. G., \& Iacobucci, G. A. (1981). Synthesis of anthocyanidins-III: Total synthesis of apigeninidin and luteolinidin chlorides. Tetrahedron, 37, 1481-1483.

Tsuda, T. (2012). Dietary anthocyanin-rich plants: Biochemical basis and recent progress in health benefits studies. Molecular Nutrition \& Food Research, 56, $159-170$.

Venn, B. J., \& Mann, J. I. (2004). Cereal grains, legumes and diabetes. European Journal of Clinical Nutrition, 58, 1443-1461.

Waterhouse, A. L. (2001). Determination of total phenolics. In R. E. Wrolstad (Ed.), Current Protocols in Food Analytical Chemistry (pp. I1.1.1-I1.1.8). New York: Wiley.

Yeomans, V. C., Linseisen, J., \& Wolfram, G. (2005). Interactive effects of polyphenols, tocopherol and ascorbic acid on the $\mathrm{Cu}^{2+}$-mediated oxidative modification of human low density lipoproteins. European Journal of Nutrition, 44, 422-428.

Yoshida, K., Mori, M., \& Kondo, T. (2009). Blue flower color development by anthocyanins: from chemical structure to cell physiology. Natural Product Reports, 26, 857-964. 